\title{
Vulnerability and Responses to Risk in Rural India ${ }^{1}$
}

\author{
Raghbendra Jha ${ }^{1}$, Woojin Kang ${ }^{2}$, Hari K. Nagarajan ${ }^{3}$ and Kailash C. Pradhan ${ }^{3}$ \\ ${ }^{1}$ Australian National University, Canberra, Australia, corresponding author r.jha@anu.edu.au \\ ${ }^{2}$ Korea Development Institute and Australian National University, Canberra, Australia \\ ${ }^{3}$ National Council for Applied Economic Research, New Delhi, India
}

\begin{abstract}
Using Vulnerability as Expected Utility (VEU) analysis that permits the decomposition of household vulnerability into its components on a unique data set this paper demonstrates that in rural India household vulnerability is most explained by poverty and idiosyncratic components. So far as risk coping strategies go households rely heavily on informal instruments such as their own saving, transfers or capital depletion. However, they also try to cope with covariate risks by participating in government programmes. Further, household consumption is highly covariate with income. This implies that existing informal insurance instruments are not sufficient to protect household consumption against income shocks. Government sponsored coping strategies reduce the idiosyncratic and risk component of vulnerability. Hence, an important policy implication of our analysis is that the government should provide readily accessible and well targeted public safety nets. The existing informal strategy is not very effective as a consumption insurance mechanism. Although the government coping programme is found to reduce vulnerability access to such programmes is constrained. Expansion of government sponsored coping programmes is likely to protect households effectively from negative shocks.
\end{abstract}

JEL Classification Code: C23, C25, C31, I32

Keywords : Vulnerability, Poverty, Covariate and Idiosyncratic shocks, REDS data, India.

Address all correspondence to:

Prof. Raghbendra Jha, ASARC,

Arndt-Corden Dept of Economics,

H.C. Coombs Building (09)

Australian National University, Canberra, ACT 0200, Australia

Phone: + 6126125 2683, Fax: + 6126125 0443,

Email: r.jha@anu.edu.au

\footnotetext{
${ }^{1}$ This paper is part of the IDRC-NCAER research program on "Building Policy Research Capacity for Rural Governance and Growth in India" (grant number 105223). We wish to thank Hans Binswanger and Andrew Foster for comments on earlier drafts. Expert assistance provided by Sudhir Kumar Singh is gratefully acknowledged. The usual caveat applies.
} 


\section{Introduction}

Households in developing countries are often confronted by various types of risks covariate (e.g. natural disasters, economic or political crisis) and idiosyncratic (e.g. illness or job-loss) shocks. When faced with such risks even non-poor members of the society can be vulnerable if it has ineffective or constrained coping instruments. To better understand the concept of vulnerability, many authors therefore emphasise (i) (exposure to) risks and (ii) instruments for ex ante risk management and ex post risk coping (or resilience) as a response to risks (Chambers, 1989; Alwang, Siegel and Jørgensen, 2001; Heitzmann, Canagarajah and Siegel, 2002; Barrientos, 2007). For example, based on Chambers's distinction between 'external' (mainly referring to risks or shocks) and 'internal' (referring to the lack of means to manage risks) vulnerability, Alwang et al (2001) and Heitzmann et al (2002) use the term, a 'risk chain' in that those two components lead to (iii) an outcome given by a welfare loss.

Accompanying this conceptual development, there has been a surge of interests in measuring household vulnerability in developing countries (e.g. Kochar, 1999; Dercon and Krishnan, 2000; Chaudhuri, Jalan and Suryahadi, 2002; McCulloch and Calandrino, 2003; Ligon and Schechter, 2003; Gaiha and Imai, 2009; Jha, Dang and Tashrifov, 2010; Kurosaki, 2010). However, many of these studies fail to assess vulnerability and test risk sharing hypothesis or to investigate household risk coping strategy for consumption smoothing. Further, very few attempts have been made to address these factors in an integrated form. As represented by a 'risk chain' hypothesis, each element is related with the other elements. Therefore, to systemically analyse household welfare under uncertainty, one needs to investigate not only household vulnerability, but also the household's risk coping strategy and the effect of the strategy on household consumption. For example, even if a household is observed as vulnerable, the household may protect itself through existing coping strategies. The effects of these coping strategies may vary with the nature of instrument adopted. Therefore, we attempt to address these points in the present study for a unique data set for rural India.

\section{Data}

The present study draws upon the ARIS/REDS survey of the NCAER. The survey, designed to be a nationally representative multi-purpose rural household and village surveys, was first collected in 1971 and subsequent rounds were conducted in 1982, 1999 and 2006. It consists 
of listing, household and village questionnaire, collecting detailed household and village information spread across various states in rural India.

The listing section provides information on a number of key household characteristics such as household income and demographics. The household questionnaire surveys information with respect to individual and household characteristics, education, labour participation, detailed incomes by sources, household expenditure, agricultural activities, land and asset ownership. The village survey provides economic and political structure, infrastructure, provision of schools, health service, financial institutions and other social services. Not only for various shocks - both aggregate and idiosyncratic - that households experiences, it also contains detailed information with respect to household coping strategy in the face of the shocks. The numbers of sample households in 1999 and 2006 surveys are 7474 and 8659 households respectively, of which 5883 households were interviewed in both rounds. To analyse household vulnerability, we use a panel of households and the final sample size are 5155 due to missing observations. The summary statistics are given in Appendix table.

Although panel data can provide richer information than cross-sectional data, there is a concern with respect to sample attrition. For simple comparison, we construct Table 1 to illustrate the sample size and the distribution across demographical groups for 1999 and 2006 cross-section data, and for panel data. As sample distributions in Table 1 shows, we find no evidence of non-random attrition that could lead to a sample bias problem.

Table 1 here.

\section{Methodology}

\subsection{Measuring Vulnerability}

There are several different definitions of vulnerability and each has its own merit. ${ }^{2}$ In the current study we define vulnerability as a household's low expected utility, so-called VEU, proposed by Ligon and Schechter (2003). VEU addresses some weaknesses of VEP, another popular measure of vulnerability.

\footnotetext{
${ }^{2}$ Three major operating definitions of vulnerability can be found in empirical literature: (i) vulnerability as expected poverty (VEP), (ii) vulnerability as low expected utility (VEU) and (iii) vulnerability as uninsured exposure to risk (VER). Hoddinott and Quisumbing (2003) provide an excellent summary on these approaches.
} 
Consider two possible states. In the first state, a risk averse household is certain that expected consumption in the next period is just below the poverty line. Therefore, the probability of poverty (i.e. vulnerability) in the state is one. In the second state, while its mean expected consumption remains unchanged, there is probability of 0.5 that the household will have consumption just above the poverty line (and above the mean) and probability of 0.5 that the household's consumption will be lower than the mean. Being risk averse, the household would prefer the first state with the certain consumption to the second state with the expected consumption despite lower vulnerability in the second state. This perverse feature of VEP is sought to be overcome by VEU measure (Hoddinott and Quisumbing, 2003). Furthermore, the VEU measure has the advantage that it enables the decomposition of estimated vulnerability into four distinct components, viz., underlying poverty, aggregate shocks, idiosyncratic shocks and unexplained risk. In any case VEU analysis is complementary to VEP analysis.

Vulnerability in the VEU measure is defined as the difference between the utility derived from some level of certainty-equivalent consumption and the expected utility derived from consumption. Therefore, it can be written as follows:

$$
V_{i}=U_{i}(z)-E U_{i}\left(c_{i t}\right)
$$

where $z$ is certainty-equivalent consumption at and above which a household would not be considered vulnerable, analogous to the poverty line. $U_{i}$ is a weakly concave, strictly increasing function.

Eq. (1) can be further decomposed as follows:

$$
\begin{array}{ll}
V_{i}=U_{i}(z)-U_{i}\left(E c_{i t}\right) & \text { (Poverty) } \\
+\left\{U_{i}\left(E c_{i t}\right)-E U_{i}\left[E\left(c_{i t} \mid \bar{X}_{t}\right)\right]\right\} & \text { (Covariate or aggregate risk) } \\
+\left\{E U_{i}\left[E\left(c_{i t} \mid \bar{X}_{t}\right)\right]-E U_{i}\left[E\left(c_{i t} \mid \bar{X}_{t}, X_{i t}\right)\right]\right\} & \text { (Idiosyncratic risk) } \\
+\left\{E U_{i}\left[E\left(c_{i t} \mid \bar{X}_{t}, X_{i t}\right)\right]-E U_{i}\left(c_{i t}\right)\right\} & \text { (Unexplained risk \& Measurement error) }
\end{array}
$$

As in Ligon and Schechter (2003), the following form of utility function is assumed:

$$
U(c)=\frac{c^{1-\kappa}}{1-\kappa}
$$

where $\kappa$ denotes the household coefficient on relative risk aversion and is set to 2 . 
We also normalise the expenditure and per capita income so that the average expenditure and per capita income over all households would be unity and set the poverty line to be one by choosing $z$ to equal average consumption. ${ }^{3}$ Therefore, household vulnerability will be zero if resources are allocated so that households receive the expected consumption expenditure with certainty (Ligon and Schechter, 2003).

$E\left(c_{i t} \mid \bar{X}_{t}\right)$ the aggregate risk component and $E\left(c_{i t} \mid \bar{X}_{t}, X_{i t}\right)$ the idiosyncratic risk component are estimated by:

$$
\begin{aligned}
& E\left(c_{i t} \mid \bar{X}_{t}\right)=\alpha_{i}+\eta_{t} \\
& E\left(c_{i t} \mid \bar{X}_{t}, X_{i t}\right)=\alpha_{i}+\eta_{t}+\beta X_{i t}
\end{aligned}
$$

In Eq. (5), if income is used as the explanatory variable for consumption as in our case, it might be endogenous, e.g., saving and liquidation of household assets (e.g. livestock) are likely to influence income as well as consumption since parts of assets are used for production (Gaiha and Imai, 2009). Hence, we use instrumental variable (IV) estimation for Eq. (5) in which income is treated as being endogenous.

\subsection{Household response to risks - choice of coping strategy}

As stated earlier, households' income and consumption fluctuate due to various risks — both aggregate and idiosyncratic shocks, and such fluctuations make households vulnerable, often compounded by the lack of (or incomplete) credit or insurance markets. To protect themselves from such unexpected shocks, households are keen to manage risks ex ante (e.g. income smoothing such as crop diversification) or cope with the consequences of the risks ex post (e.g. consumption smoothing through precautionary saving or transfer etc.).

To investigate households' response to shocks, a multivariate probit model is applied here because households often choose different coping instrument at the same time in the face of risks and the model allows correlation between such choices.

The latent decision variable for coping instruments $R_{i m}^{*}$ is assumed to be a function of household characteristics, $X_{i m}$ and an error term $\varepsilon_{i m}$.

\footnotetext{
${ }^{3}$ Household consumption expenditure and income in 2006 data were adjusted at 1999 value using state wise CPI for agriculture and rural labourers.
} 


$$
R_{i m}^{*}=\vartheta_{m} X_{i m}+\varepsilon_{i m}
$$

The error term $\varepsilon_{i m}$ has a multivariate normal distribution, each with a zero mean and variancecovariance matrix $V$, where $V$ has values of 1 on the principal diagonal and correlations $\rho_{m n}=\rho_{n m}$ as off-diagonal elements (Cappellari and Jenkins, 2003).

$$
R_{i m}=1 \text { if } R_{i m}^{*}>0 \text {, and } 0 \text { otherwise }
$$

Since a household's decision on coping strategies relies on not only household characteristics but also the nature of the risks faced, a vector of shock variables (dummy) is included in the model. These are: (i) aggregate (drought, floods, livestock epidemic, and epidemic) and idiosyncratic (death of household members, health problems, and crop failure) shocks. The estimation is carried out, drawing upon 2006 data only because of the lack of information on coping mechanisms in 1999.

For household coping strategy against shocks, we classified household responses into 5 categorises: (i) Saving, (ii) participating in government program, (iii) Borrowing/Transfer, (iv) Capital depletion and (v) other responses.

\subsection{Measure of consumption insurance}

Although household attempt to manage ex ante or ex post risk by formal and informal risk management schemes (e.g. precautionary saving, mutual insurance etc.) the extent of consumption smoothing depends on the quality of the existing mechanism. A useful way to investigate the effectiveness of the mechanism is to estimate the following model:

$$
\Delta \ln c_{i v t}=\phi+\gamma \Delta \ln y_{i v t}+\psi \Delta\left(\overline{\ln y_{v t}}\right)+\delta X_{i v t}+\Delta \varepsilon_{i v t}
$$

where $\Delta \ln c_{i v t}$ and $\Delta \ln y_{i v t}$ denote the growth rate of household consumption and income respectively. $\Delta\left(\overline{\ln y_{v t}}\right)$ represents the growth rate of average village (or state) income and is treated as a proxy of aggregate shocks (Townsend, 1994)

The estimate of $\gamma$ on which much of the empirical literature focuses indicates whether the insurance mechanism is effective within villages (states). If complete insurance or risk 
sharing exists, $\gamma$ is expected to be zero and significant. Thus, the higher values of $\gamma$ would be an evidence of weak consumption insurance against income risks. ${ }^{4}$

As a measure of welfare, food consumption is frequently used in regions where a substantial fraction of the population devotes more than three quarters of their expenditure to food (Deaton, 1997). In such a society, households are expected to be conservative in maintaining the level of consumption expenditure and hence, expenditure devoted to food is likely to be less covariate with income than other components of expenditure as often reflected by the Engel curve in developing countries.

Our data also show that the share of food consumption to total consumption expenditure are quite high (57.7\% in 1999 and 53.8\% in 2006) and these high shares suggest the possibility that households might be keen to insure their food consumption against negative shocks. Therefore, we will use three different dependent variables (total consumption, food consumption, non-food consumption expenditure).

\section{Result}

\section{(a) Measure of VEU}

Table 2 shows results from our estimation of Eq. (4). ${ }^{5}$

\section{Table 2 here.}

The coefficient estimate, negative and strongly significant, of time dummy for year 1999 indicates that aggregate risk is mostly explained by a positive shock. i.e., rural India has enjoyed economic growth between 1999 and 2006. We also observe that households in a reserved village would have higher per capita consumption expenditure relative to those in a village never reserved though the coefficient is found to be significant for the twice reserved

\footnotetext{
${ }^{4}$ We interpret $\gamma$ as a measure of consumption insurance rather than a measure of vulnerability done in VER measure. VER model assumes that positive and negative shocks have symmetric effects. However, ability dealing with positive shocks (e.g. accumulating assets or saving etc.) compared to negative shocks (selling assets or receiving transfers etc.) is likely to different among households. Therefore, in order to interpret $\gamma$ as a measure of vulnerability it is suggested to replace $\Delta \ln y_{\text {ivt }}$ with two covariates denoting absolute values of the size of positive and negative income changes (Hoddinott and Quisumbing, 2003).

${ }^{5}$ Definitions of all variables used and summary statistics thereon are given in the Appendix Table.
} 
village. The dummy variables of agro climatic condition (Arid region is the reference) show that humid and semi-arid tropics are positively associated with household consumption. ${ }^{6}$

Table 3 provides results obtained from Panel IV estimation of Eq. (5). Income is instrumented in the first stage by the per capita number of productive assets (e.g. tractors) and the share of the area of irrigated land to total land a household owned. Although the possible effects of these variables on household consumption cannot be denied, it might be reasonable that they first affect household income. Same type of instruments for income is also specified in Gaiha and Imai (2009) and Jha et al (2010). As shown from the Table 3, Hansen-Sargan statististic of overidentification test indicates that the instruments used here are valid.

\section{Table 3 here.}

In the first stage estimation, female headship is positively associated with a household's income and its coefficient is significant at the $5 \%$ level. In contrast, the coefficient estimate of female share in the household is negative and strongly significant, implying that a household with many female members tends to have lower per capita income. This may suggest that although high economic growth took place during the period 1999-2006, less economic opportunities for women have been generated. The positive and significant coefficient estimate of its square term suggests a non-linear association between the share of female members and per capita household income. We cannot find any evidence of life cycle effects, partly captured by age of household head and its square term. The negative coefficient of share of members with high secondary or higher education, and the positive coefficient of its square term suggests that although education has a positive impact on household income, relationship is shown to be convex. Table 3 also shows the strong evidence of a hump-shaped relationship between a household's productive assets and a household income. As we expect, higher share of irrigated land to total land would increase household per capita income.

Turning to the second stage estimation, the size of coefficient estimate of predicted per capita income, strongly significant at $1 \%$, suggests that a household's consumption is determined largely by its income. The negative and significant coefficient estimate of dependency

\footnotetext{
${ }^{6}$ The present study uses ICRISAT definition of agro climatic condition. Classification is given in summary statistics in Appendix.
} 
implies that a household with many old or young members tend to have lower per capita consumption expenditure. The higher share of educated members, the higher the per capita consumption. However, we find no evidence of non-linear effects on consumption whereas strong non-linearity is observed in the first stage income estimation. The supply of public goods is positively associated with household consumption and the coefficient is significant at $5 \%$. This, together with the negative association, though insignificant, between public good and household income, implies that the provision of public good tends to promote household consumption but not necessarily household income. The positive and strongly significant both economically and statistically — coefficient estimates of humid and semi-arid regional dummies suggest that climatic condition is an important factor in determining the level of household consumption.

The results obtained from Eq. (4) and (5) are used to derive VEU. We now decompose the average VEU into 4 distinct components as discussed earlier. The various components are shown in Table 4.

\section{Table 4 here.}

The estimate of average VEU (0.3016) implies that the average rural Indian household has experienced about $30 \%$ of utility loss due to poverty (e.g. low physical and human capital) or inequality, and various risks during 1999-2006. The negative sign of covariate risk component suggests that the utility loss would have been higher if there was no economic growth in rural India during the sample period. Covariate shock raised VEU (largely because of higher economic growth). We observe from Table 4 that average household vulnerability during 1999-2006 was mainly due to low living standards and idiosyncratic shocks whereas the covariate shock reduced vulnerability.

\section{(b) Household response to risk}

Table 5 provides results obtained from multivariate probit estimation, drawing upon the 2006 survey, to investigate the choice of household coping strategy. Panel (A) uses idiosyncratic and covariate shock at the aggregate level whereas panel (B) and (C) use shock variables at 
the disaggregated level. ${ }^{7}$ Other explanatory variables used in the model are the same as in Table 3. ${ }^{8}$ We used Huber-White sandwich estimator to overcome heteroskedasticity.

\section{Table 5 here.}

We now provide a summary of the findings. ${ }^{9}$ First, it is observed from panels (A)-(B) that the main coping mechanism of the rural Indian household is running down its own saving. Regardless of model specifications based on the types of shocks used, it shows the highest probability among the defined household coping strategies. Second, panel (A) shows that household is likely to choose borrowing or transfer from its relatives or friends in the face of idiosyncratic shocks whereas it relies on capital depletion when it faces covariate shocks. ${ }^{10}$ This choice of coping strategy seems to be sensible in that as covariate shock affects other residents within the village as well as the household under consideration; it is less likely that the household will rely on transfer as a coping strategy. Therefore, the household would be forced to sell its assets, reduce consumption or withdraw children from school. Similar findings are also observed from panel (B) where disaggregated shock variables are included. Third, although the household is less likely to choose a government provided coping programme when it faces idiosyncratic shock, the probability sharply increases if it is affected by covariate shock (both coefficient estimates of idiosyncratic and covariate shocks in the government programme are significant in Panel (A)). However, when we use each of specific type of shock variables, the coefficient estimates of idiosyncratic shocks in the government programme become insignificant while those of covariate shocks are still significant. Comparing the probability of choice of the government programme with those of other coping strategies, rural Indian households manage risks through their own or informal strategies.

\footnotetext{
${ }^{7}$ For example, if a household has experienced any shock among drought, floods, livestock epidemic and epidemic, then the dummy of covariate shock in panel (A) takes one. Similarly, idiosyncratic shock takes one if the household has in the past faced either death of its members, sudden health problem or crop failure.

${ }^{8}$ For the sake of convenience, we provide the results with respect to shocks variables and public goods, which are the main focus of estimation. The full table will be furnished upon request.

${ }^{9}$ Full results will be furnished upon request.

${ }^{10}$ Capital depletion is defined if a household chooses, as a coping strategy, either selling assets, withdrawal of children education, reducing consumption or change crop choice. The elements of capital depletion all would affect household future income. For example, reducing consumption would lower labour productivity through inadequate nutrition intake. Change in crop choice would also result in low risk and low expected income. Therefore, these strategies are aggregated as capital depletion as its consequence is likely to different from other coping strategies.
} 


\section{(c) Measure of consumption insurance}

As Table 5 only provides the household response to risks, not whether household could effectively insure their consumption, we estimated Eq. (8) by IV estimation for the measure of insurance. Results are given in Table 6. As in Table 3, the change of household income is treated as being endogenous and was instrumented by the change in per capita productive assets, its square and the change in the share of irrigated land. Estimations were carried out at the village level. The upper panel of Table 6 presents the results of first stage estimation of IV estimation whereas the lower panel show second stage estimation. The results of diagnostic tests (e.g. Durbin-Wu-Hausman test for endogeneity) support the use of IV estimation and instruments.

\section{Table 6 here.}

As noted earlier, if there is complete insurance or risk sharing within villages the coefficient estimates of the change in log of household income would be zero and significant, and that of the change in village mean of log income would be non-zero and significant. Although complete risk sharing is often rejected, much empirical literature has observed partial risk sharing within villages (e.g. Townsend, 1994). Our results show that the growth of consumption is highly covariate with the growth of income, suggesting that although households rely mainly on informal risk-coping instruments, the strategies adopted by households are less effective. Furthermore, the negative and significant coefficient estimate for the change of village mean of log income suggests that there is no risk sharing mechanism within villages. ${ }^{11}$

The constrained access to efficient risk management mechanisms among households implies that there is substantial risk of increase in the rural transient poor in the face of shocks. Besides, our finding from the multivariate probit model (Table 5) that one of the significant households coping strategies is capital depletion - selling productive assets, reducing consumption or withdrawal of children from school - might induce prolonged consequences for household welfare, and may trap them in poverty.

\footnotetext{
${ }^{11}$ As our results are based on rural representative data, it is not necessarily contradict from the finding of partial risk sharing in other studies of which many draws upon the selected sample village data with mostly annual consumption and income data. Our results are similar with the findings observed in Shirapur and Kanzara villages in Gaiha and Imai (2009).
} 
Comparing the coefficients of estimates for food consumption and non-food consumption estimations (the second vs. the third columns), the smaller coefficient estimates of the change of log income in food consumption, though this difference is not large, is likely to suggest that households are keener to insure food consumption than non-food consumption from income shocks.

\section{Policy implications and conclusions}

Using a VEU analysis that permits the decomposition of household vulnerability into its components this paper has demonstrated that in rural India household vulnerability is mostly explained by poverty and idiosyncratic components. So far as risk coping strategies go households rely heavily on informal instruments such as their own saving, transfers or capital depletion. However, they also try to cope with covariate risks by participating in government programmes.

Further, household consumption is highly covariate with income. This implies that existing informal insurance instruments are not sufficient to protect household consumption against income shocks. Government sponsored coping strategies reduce the idiosyncratic and risk component of vulnerability.

Hence, an important policy implication of our analysis is that the government should provide readily accessible and well targeted public safety nets. The existing informal strategy is not very effective as a consumption insurance mechanism. Although the government coping programme is found to reduce vulnerability induced by idiosyncratic shocks access to such programmes is constrained. Expansion of government sponsored coping programmes is likely to protect households efficiently from negative shocks. 


\section{References}

Alwang, J. Siegel, P.B. and S.L. Jørgensen (2001) 'Vulnerability: A View from Different Disciplines', Social Protection Discussion Paper Series No. 0115, The World Bank.

Barrientos, A. (2007) ‘Does Vulnerability Create Poverty Traps?’, CPRC Working Paper No.76.

Becker, S. and A. Ichino (2002) 'Estimation of Average Treatment Effects based on Propensity Scores’, The Stata Journal, 2(4), pp. 358-77.

Cappellari, L., and S. P. Jenkins (2003) 'Multivariate Probit Regression Using Simulated Maximum Likelihood’, The Stata Journal, 3(3), pp. 278-94.

Chambers, R. (1989) Editorial Introduction: Vulnerability, Coping and Policy, Institute of Development Studies Bulletin, 20(2), p.1-7.

Chaudhuri, S., Jalan J. and A. Suryahadi (2002) 'Assessing Household Vulnerability to Poverty: A Methodology and Estimates for Indonesia’, Discussion Paper, No. 0102-52, Columbia University.

Deaton, A. (1997) The Analysis of Household Surveys: A Microeconometric Approach to Development Policy, Baltimore and London: The Johns Hopkins University Press.

Dercon, S., and P. Krishnan (2000) 'In Sickness and in Health: Risk-Sharing within Households in Rural Ethiopia', Journal of Political Economy, 108, pp. 688-727.

Gaiha, R., and K. Imai (2009) 'Measuring Vulnerability and Poverty in Rural India', in I.W. Naudé, A. Santos-Paulino and M. McGillivray (eds) Vulnerability in Developing Countries, UNU-WIDER, United Nation University Press.

Heitzmann, K., Canagarajah, R.S., and P.B. Siegel (2002) 'Guidelines for Assessing the Sources of Risk and Vulnerability’, Social Protection Discussion Paper Series No. 0218, The World Bank.

Hoddinott, J., and A. Quisumbing (2003) 'Methods for Microeconometric Risk and Vulnerability Assessments’, Social Protection Discussion Paper Series No.0324, The World Bank.

Jha, R., Imai, K., and R. Gaiha (2009) 'Poverty, Undernutrition and Vulnerability in Rural India: Public Works versus Food Subsidy’, CPRC Working Paper No. 135.

Jha, R., Dang, T., and Y. Tashrifov (2010) 'Economic Vulnerability and Poverty in Tajikistan’, Economic Change and Restructuring, 43(2), pp. 95-112.

Kochar, A. (1999) 'Smoothing Consumption by Smoothing Income: Hours-of-Work Responses to Idiosyncratic Agricultural Shocks in Rural India’, The Review of Economics and Statistics, 81(1), pp. 50-61.

Kurosaki, T. (2010) 'Targeting the Vulnerable and the Choice of Vulnerability Measure: Review and Application to Pakistan’, PRIMCED Discussion Paer Series No.1.

Ligon, E and L. Schechter (2003) 'Measuring Vulnerability’, The Economic Journal, 113, pp. 95-102.

McCulloch, N. and M. Calandrino (2003) 'Vulnerability and Chronic Poverty in Rural Sichuan’, World Development, 31(3), pp. 611-28

Swain, R.B., and M. Floro (2010) 'Reducing Vulnerability through Microfinance: Evidence from Indian Self Help Group Program’, Working Paper 2010:23, Uppsala University.

Townsend, M.R. (1994) 'Risk and Insurance in Village India’, Econometrica, 62, pp. 539-91. 
Table 1. Sample size and Distribution

\begin{tabular}{|c|c|c|c|c|}
\hline & \multicolumn{2}{|c|}{ Cross-Section } & \multicolumn{2}{|c|}{ Panel } \\
\hline & 1999 & 2006 & 1999 & 2006 \\
\hline Total observations & 7474 & 8659 & 5883 & 5883 \\
\hline \multicolumn{5}{|c|}{ Household head age (\%) } \\
\hline Less than 30 & 9.6 & 5.5 & 9.0 & 4.7 \\
\hline $31-40$ & 24.2 & 20.8 & 23.2 & 20.1 \\
\hline $41-50$ & 23.5 & 27.9 & 23.8 & 27.7 \\
\hline $51-60$ & 20.6 & 22.0 & 22.4 & 22.0 \\
\hline $61-70$ & 15.8 & 16.8 & 16.5 & 17.7 \\
\hline Greater than 70 & 6.3 & 7.1 & 5.1 & 7.8 \\
\hline Male head (\%) & 93.4 & 89.4 & 94.5 & 90.0 \\
\hline Female head (\%) & 6.6 & 10.6 & 5.5 & 10.0 \\
\hline Head married (\%) & 87.9 & 86.5 & 88.1 & 86.8 \\
\hline Unmarried $\quad(\%)$ & 12.1 & 13.5 & 11.9 & 13.2 \\
\hline ST household (\%) & 12.71 & 16.51 & 13.19 & 14.64 \\
\hline SC household (\%) & 6.48 & 8.11 & 4.84 & 7.55 \\
\hline OBC household (\%) & 47.46 & 46.63 & 48 & 47.03 \\
\hline OC household (\%) & 33.36 & 28.75 & 33.97 & 30.78 \\
\hline Hindu (\%) & 88.5 & 88.6 & 89.6 & 88.8 \\
\hline Muslim (\%) & 6.9 & 6.0 & 6.0 & 5.8 \\
\hline Sikh (\%) & 2.8 & 3.3 & 2.9 & 3.2 \\
\hline Christian (\%) & 1.4 & 1.5 & 1.2 & 1.5 \\
\hline Jain (\%) & 0.03 & 0.2 & 0.02 & 0.2 \\
\hline Buddhist (\%) & 0.4 & 0.4 & 0.4 & 0.4 \\
\hline
\end{tabular}

Source: REDS 1999 and 2006 
Table 2: Covariate risk component (Panel Random effect)

\begin{tabular}{lc}
\hline & Per capita household consumption \\
\hline yr99 & $-\mathbf{0 . 1 2 5}(\mathbf{1 1 . 5 9})^{\star * *}$ \\
once_res & $0.029(1.14)$ \\
twice_res & $\mathbf{0 . 0 5 8}(\mathbf{1 . 8 7})^{\star}$ \\
Humid area & $\mathbf{0 . 2 0 1}(\mathbf{2 . 1 8})^{\star *}$ \\
Semi-Arid temperate & $0.071(0.61)$ \\
Semi-Arid tropic & $\mathbf{0 . 2 2 9}(\mathbf{2 1 5})^{\star \star *}$ \\
Constant & $0.862(9.09)$ \\
Observations & 11727 \\
R-squared & 0.03 \\
\hline Observations & 11729 \\
Joint significance & $\mathrm{F}(6,5839)=30.52$ \\
Prob > chi2 & 0.0000 \\
\hline
\end{tabular}

Absolute value of $t$ statistics in parentheses

${ }^{*}$ significant at $10 \%$; ${ }^{* *}$ significant at $5 \%$; ** significant at $1 \%$

1. village never reserved is the reference group

2. Arid area is the reference group

Source: REDS 1999 and 2006 
Table 3: Idiosyncratic risk component (Panel fixed effects IV model)

\begin{tabular}{|c|c|c|}
\hline & $\begin{array}{l}\text { First stage } \\
\text { p. c. income }\end{array}$ & $\begin{array}{l}\text { Second stage } \\
\text { p.c. consumption }\end{array}$ \\
\hline Ipcincome & & $0.408(11.12)^{* \star *}$ \\
\hline fhead & $0.212(200)^{* *}$ & $-0.042(0.79)$ \\
\hline age & $0.013(1.06)$ & $-0.008(1.32)$ \\
\hline age2 & $0.000(0.82)$ & $0(1.09)$ \\
\hline femaleshare & $-2.553(3.51)^{\star \star \star}$ & $0.418(1.09)$ \\
\hline femaleshare2 & $2.578(3.76)^{\star \star \star}$ & $-0.574(1.56)$ \\
\hline dependency & $-0.124(1.12)$ & $-0.242(4.34)^{\star \star \star}$ \\
\hline seconedushare & $-1.144(4.94)^{\star \star \star}$ & $0.236(186)^{\star}$ \\
\hline seconedushare2 & $0.944(4.48)^{\star \star *}$ & $-0.035(0.31)$ \\
\hline yr99 & $-0.133(1.88)^{\star}$ & $0.052(1.44)$ \\
\hline pubgoods_hh & $-0.009(1.07)$ & $0.01(2.50)^{\star \star}$ \\
\hline once_res & $0.120(1.55)$ & $0.023(0.61)$ \\
\hline twice_res & $0.280(289)^{* \star *}$ & $-0.008(0.17)$ \\
\hline Humid & $-0.233(0.82)$ & $0.432(3.09)^{\star \star \star}$ \\
\hline SA_temperate & $-0.015(0.04)$ & $0.233(1.28)$ \\
\hline SA_tropic & $-0.243(0.74)$ & $0.428(2.64)^{\star \star \star}$ \\
\hline pcasset & $0.227(13.19)^{\star \star \star}$ & \\
\hline (pcasset)2 & $-0.001(11.03)^{\star \star \star}$ & \\
\hline land_irrigate & $0.189(294)^{\star \star \star ~}$ & \\
\hline Constant & $1.001(2.04)$ & $0.266(1.05)$ \\
\hline Observations & & \\
\hline Joint significance & $\begin{array}{c}F(18,4959)=20.02 \\
\text { Prob }>F=0.0000\end{array}$ & $\begin{array}{c}\text { Wald chi2 } 2(16)=18406.58 \\
\text { Prob }>\text { chi } 2=0.0000\end{array}$ \\
\hline $\begin{array}{l}\text { Hausman Test: fixed effects vs. random } \\
\text { effect }\end{array}$ & \multicolumn{2}{|c|}{$\begin{array}{l}\text { Wald chi } 2(15)=34.63 \\
\text { Prob }>\text { chi } 2=0.0028\end{array}$} \\
\hline $\begin{array}{l}\text { Sargan-Hansen test for } \\
\text { overidentification restriction }\end{array}$ & \multicolumn{2}{|c|}{$\begin{aligned} \text { Chi2 } 2(2) & =0.996 \\
\text { Prob }>\text { ch2 } & =0.6077\end{aligned}$} \\
\hline
\end{tabular}

Table 4: Decomposition of average vulnerability

\begin{tabular}{|c|c|c|c|c|c|c|c|c|}
\hline VEU & $=$ & Poverty & + & $\begin{array}{c}\text { Covariate } \\
\text { risk }\end{array}$ & + & $\begin{array}{l}\text { Idiosyncratic } \\
\text { risk }\end{array}$ & + & $\begin{array}{l}\text { Unexplained } \\
\text { risk }\end{array}$ \\
\hline 0.3016 & & 0.2103 & & -0.1996 & & 0.196 & & 0.0949 \\
\hline
\end{tabular}

Source: REDS 1999 and 2006 
Table 5: Multivariate Probit model: Household coping strategy (Shock variables - Dummy)

\begin{tabular}{|c|c|c|c|c|c|}
\hline HH coping strategy & Saving & Government & Transfer & Capital depletion & Other \\
\hline & \multicolumn{5}{|c|}{ Panel (A) } \\
\hline idiosyncratic & $1.516(28.63)^{\star \star \star}$ & $0.239(3.46)^{\star \star \star}$ & $0.825(14.58)^{\star \star \star}$ & $0.505(9.12)^{\star \star \star}$ & $-2.553(27.72)^{\star \star \star}$ \\
\hline \multirow[t]{2}{*}{ covariate } & $1626(35.11)^{\star * *}$ & $0.873(1287)^{\star \star *}$ & $0.326(6.45)^{\star \star \star}$ & $0.948(18.15)^{\star \star \star}$ & $-2608(30.14)^{\star \star \star k}$ \\
\hline & \multicolumn{5}{|c|}{ Panel (B) } \\
\hline death & $1.516(14.39)^{\star \star *}$ & $-0.004(0.03)$ & $0.362(3.99)^{\star \star \star}$ & $0.122(1.09)$ & $-1.919(15.26)^{\star \star *}$ \\
\hline health & $1363(14.59)^{\star \star *}$ & $-0.015(0.10)$ & $0.891(10.16)^{\star \star *}$ & $0.213(2.10)^{\star *}$ & $-2.252(14.02)^{\star \star \star}$ \\
\hline cropfail & $0.982(12.21)^{\star * *}$ & $0.086(0.80)$ & $0.205(2.49)^{* *}$ & $0.599(7.74)^{\star * *}$ & $-1.468(14.43)^{\star \star *}$ \\
\hline drought & $1329(23.76)^{\star \star *}$ & $0.125(1.65)^{*}$ & $0.333(5.56)^{\star \star *}$ & $0.603(10.66)^{\star \star *}$ & $-1.906(23.15)^{\star \star \star}$ \\
\hline floods & $1089(16.45)^{\star \star \star}$ & $0.99(14.08)^{\star * *}$ & $0.076(1.06)$ & $0.898(14.24)^{* \star *}$ & $-2.155(21.03)^{\star \star *}$ \\
\hline livestk & $1.265(9.15)^{\star \star *}$ & $0.543(3.64)^{\star * *}$ & $0.605(5.68)^{\star \star *}$ & $0.295(2.30)^{\star \star}$ & $-1.799(9.95)^{\star \star *}$ \\
\hline epidemic & $0.761(5.47)^{\star \star \star}$ & $-0.338(1.26)$ & $-0.439(2.70)^{* \star *}$ & $0.267(2.04)^{\star *}$ & $0.046(0.29)$ \\
\hline Observations & 5,558 & 5,558 & 5,558 & 5,558 & 5,558 \\
\hline Joint significance & \multicolumn{5}{|c|}{ (A) $\operatorname{chi} 2(65)=4765.61,(B) \operatorname{chi} 2(75)=3752.18,(C) \operatorname{chi} 2(90)=3263.79$} \\
\hline
\end{tabular}

Robust z-statistics in parentheses

* significant at $10 \%$; ${ }^{* *}$ significant at $5 \% ;{ }^{* * *}$ significant at $1 \%$

Source: REDS 1999 and 2006 
Table 6: Measure of consumption insurance (IV estimation - Second stage estimation provided)

\begin{tabular}{|c|c|c|c|}
\hline First stage & $\Delta$ lpcincome & $\Delta$ pcincome & $\Delta$ lpcincome \\
\hline$\Delta$ mean of Ipcincome & $0.625(30.33)^{\star \star *}$ & $0.625(30.33)^{\star \star *}$ & $0.625(30.35)^{\star \star *}$ \\
\hline Age & $0.003(0.45)$ & $0.003(0.45)$ & $0.003(0.45)$ \\
\hline Age2 & $0.000(0.21)$ & $0.000(0.21)$ & $0.000(0.2)$ \\
\hline$\Delta$ Femaleshare & $-1.486(4.53)^{\star \star *}$ & $-1.486(4.53)^{\star \star \star *}$ & $-1.484(4.52)^{* \star *}$ \\
\hline$\Delta$ Femaleshare2 & $1.475(4.84)^{* \star *}$ & $1.475(4.84)^{\star \star \star}$ & $1473(4.84)^{\star \star \star}$ \\
\hline$\Delta$ Dependency & $-0.013(0.17)$ & $-0.013(0.17)$ & $-0.014(0.19)$ \\
\hline$\Delta$ Seconedushare & $-0.550(5.16)^{\star * *}$ & $-0.550(5.16)^{\star \star *}$ & $-0.549(5.15)^{\star \star *}$ \\
\hline$\Delta$ Seconedushare2 & $0.520(5.35)^{\star \star *}$ & $0.520(5.35)^{\star \star *}$ & $0.518(5.33)^{\star \star \star}$ \\
\hline$\Delta$ no_GS & $-0.008(0.29)$ & $-0.008(0.29)$ & $-0.008(0.29)$ \\
\hline$\Delta$ no_voting & $-0.031(3.32)^{* * *}$ & $-0.031(3.32)^{\star * *}$ & $-0.031(3.33)^{* \star *}$ \\
\hline$\Delta$ regime_jati & $-0.046(0.73)$ & $-0.046(0.73)$ & $-0.046(0.74)$ \\
\hline$\Delta$ regime_gender & $-0.036(1.29)$ & $-0.036(1.29)$ & $-0.035(1.27)$ \\
\hline$\Delta$ pcasset & $0.113(15.69)^{\star \star *}$ & $0.113(15.69)^{\star \star * *}$ & $0.113(15.7)^{\star \star \star}$ \\
\hline ( $\Delta$ pcasset) 2 & $-0.001(13.26)^{\star \star \star}$ & $-0.001(13.26)^{\star \star *}$ & $-0.001(13.27)^{\star \star *}$ \\
\hline$\Delta$ land_irrigate & $-0.034(0.68)$ & $-0.034(0.68)$ & $-0.035(0.69)$ \\
\hline Constant & $0.017(0.09)$ & $0.017(0.09)$ & $0.017(0.09)$ \\
\hline Joint significance & $F(15,5141)=87.41$ & $F(15,5140)=87.38$ & $F(15,5139)=87.50$ \\
\hline Prob> F & 0.0000 & 0.0000 & 0.0000 \\
\hline Second stage & $\Delta$ pcex & $\Delta$ pcex_f & $\Delta$ pcex_nf \\
\hline$\Delta$ lpcincome & $0.677(13.73)^{* \star *}$ & $0.657(13.48)^{* * *}$ & $0.692(11.92)^{\star \star \star * k}$ \\
\hline$\Delta$ mean of Ivillpcincome & $-0.431(12.59)^{\star \star \star}$ & $-0.406(11.98)^{\star \star *}$ & $-0.45(11.15)^{\star \star \star}$ \\
\hline Age & $0.004(0.75)$ & $0.004(0.68)$ & $0.004(0.64)$ \\
\hline Age2 & $0(0.81)$ & $0(0.69)$ & $0(0.71)$ \\
\hline$\Delta$ Femaleshare & $0.353(1.29)$ & $0.527(1.95)^{\star}$ & $0.08(0.25)$ \\
\hline$\Delta$ Femaleshare2 & $-0.489(1.90)^{\star}$ & $-0.601(2.36)^{\star \star}$ & $-0.288(0.95)$ \\
\hline$\Delta$ Dependency & $-0.062(1.08)$ & $-0.062(1.09)$ & $-0.044(0.64)$ \\
\hline$\Delta$ Seconedushare & $0.331(3.66)^{\star \star \star}$ & $0.269(3.00)^{\star \star \star}$ & $0.492(4.62)^{\star \star \star}$ \\
\hline$\Delta$ Seconedushare2 & $-0.146(1.75)^{*}$ & $-0.116(1.41)$ & $-0.251(256)^{\star \star}$ \\
\hline$\Delta$ no_GS & $0.049(2.38)^{\star \star}$ & $0.037(1.83)^{\star}$ & $0.065(2.67)^{\star \star *}$ \\
\hline$\Delta$ no_voting & $0.014(184)^{\star}$ & $0.021(2.78)^{\star \star \star}$ & $0.002(0.20)$ \\
\hline$\Delta$ regime_jati & $0.054(1.12)$ & $0.12(2.52)^{\star *}$ & $-0.012(0.21)$ \\
\hline$\Delta$ regime_gender & $0.059(2.77)^{* * *}$ & $0.065(3.07)^{\star \star \star *}$ & $0.055(2.19)^{\star * *}$ \\
\hline Constant & $-0.267(1.83)$ & $-0.327(2.27)$ & $-0.199(1.16)$ \\
\hline Observations & 5157 & 5156 & 5155 \\
\hline Joint significance & $F(13,5143)=22.05$ & $F(13,5142)=20.33$ & $F(13,5141)=18.59$ \\
\hline Prob $>F$ & 0.0000 & 0.0000 & 0.0000 \\
\hline $\begin{array}{l}\text { Durbin-Wu-Hausman } \\
\text { test of Endogeneity }\end{array}$ & $\operatorname{chi} 2(1)=270.89$ & $\operatorname{chi} 2(1)=241.65$ & $\operatorname{chi} 2(1)=152.26$ \\
\hline Prob> chi2 & 0.0000 & 0.0000 & 0.0000 \\
\hline $\begin{array}{l}\text { Anderson canonical } \\
\text { correlation LR statistic }\end{array}$ & $\operatorname{chi} 2(3)=241.700$ & $\operatorname{chi} 2(3)=241.653$ & $\operatorname{chi} 2(3)=242.11$ \\
\hline Prob> chi2 & 0.0000 & 0.0000 & 0.0000 \\
\hline Sargan test statistic & Chi2(2)= 2.672 & Chi2(2) $=3.677$ & Chi2(2)= 2.023 \\
\hline Prob> chi2 & 0.2629 & 0.1590 & 0.3637 \\
\hline
\end{tabular}

Absolute value of $t$ statistics in parentheses

* significant at $10 \%$; ${ }^{* *}$ significant at $5 \%$; ${ }^{* *}$ significant at $1 \%$

Source: REDS 1999 and 2006 
Appendix: Summary statistics

\begin{tabular}{|c|c|c|c|c|c|}
\hline Variable & Description & Mean & Std. Dev. & Min & Max \\
\hline Ipcincome & log (per capita household income) & 8.414 & 0.927 & 2.894 & 12.899 \\
\hline Ipcex & $\log$ (per capita HH total consumption expenditure) & 8.602 & 0.508 & 6.494 & 11.394 \\
\hline Ipcex_f & log (per capita HH food consumption expenditure) & 8.044 & 0.466 & 5.783 & 11.061 \\
\hline Ipcex_nf & log (per capita HH non-food consumption expenditure) & 7.685 & 0.661 & 4.534 & 11.276 \\
\hline fhead & 1 if a household is headed by female, otherwise 0 & 0.075 & 0.263 & 0 & 1 \\
\hline age & age of household head & 50.078 & 13.344 & 21 & 100 \\
\hline femaleshare & Share of female members & 0.481 & 0.157 & 0.111 & 1 \\
\hline dependency & Share of household members aged below 14 or above 65 & 0.362 & 0.235 & 0 & 1 \\
\hline seconedushare & Share of household members with high secondary education or higher & 0.437 & 0.372 & 0 & 1 \\
\hline pcasset & per capita number of productive asset including livestocks & 2.132 & 3.016 & 0 & 57 \\
\hline land_irrigate & the ratio of the irrigated land to total land size & 0.399 & 0.466 & 0 & 1 \\
\hline no_GS & Number of participation in Gram Sabha meetings taken by household members & 0.625 & 0.941 & 0 & 5 \\
\hline no_voting & Number of participation in voting taken by household members & 5.333 & 2.451 & 0 & 11 \\
\hline Pubgoods_hh & number of village public goods availablity (per household) & 0.053 & 0.032 & 0.008 & 0.253 \\
\hline Ivillpcincome & Log (per capita village income) & 8.511 & 0.481 & 6.873 & 9.762 \\
\hline no_res & 1 if a household is located in avillage never reserved & 0.152 & 0.359 & 0 & 1 \\
\hline once_res & 1 if a household is located in avillage once reserved & 0.372 & 0.483 & 0 & 1 \\
\hline no_res & 1 if a household is located in avillage twice reserved & 0.391 & 0.488 & 0 & 1 \\
\hline$\Delta$ regime_jati & 1 if jati of a pradhan was changed & 0.051 & 0.220 & 0 & 1 \\
\hline$\Delta$ regime_jati & 1 if gender of a pradhan was changed & 0.474 & 0.499 & 0 & 1 \\
\hline humid* & 1 if a household is located in humid region & 0.299 & 0.458 & 0 & 1 \\
\hline SA_temperature* & 1 if a household is located in semi-arid temperature region & 0.244 & 0.430 & 0 & 1 \\
\hline SA_tropic* & 1 if a household is located in semi-arid tropic region & 0.393 & 0.488 & 0 & 1 \\
\hline arid $^{*}$ & 1 if a household is located in arid region & 0.152 & 0.246 & 0 & 1 \\
\hline \multicolumn{6}{|c|}{ Shock variables (Dummy) } \\
\hline covariate & $\begin{array}{l}1 \text { if a household was affected by either drought, floods, epidemic or livestock } \\
\text { epidemic }\end{array}$ & 0.369 & 0.483 & 0 & 1 \\
\hline drought & 1 if a household was affected by drought & 0.222 & 0.415 & 0 & 1 \\
\hline floods & 1 if a household was affected by floods & 0.154 & 0.361 & 0 & 1 \\
\hline epidemic & 1 if a household was affected by epidemic & 0.035 & 0.184 & 0 & 1 \\
\hline livestk & 1 if a household was affected by livestock epidemic & 0.040 & 0.195 & 0 & 1 \\
\hline idiosyncratic & $\begin{array}{l}1 \text { if a household was affected by death of } \mathrm{HH} \text { members, sudden health problem or } \\
\text { crop failure }\end{array}$ & 0.326 & 0.469 & 0 & 1 \\
\hline death & 1 if a household was affected by death of $\mathrm{HH}$ members & 0.065 & 0.246 & 0 & 1 \\
\hline health & 1 if a household was affected by sudden health problem & 0.083 & 0.275 & 0 & 1 \\
\hline crop failure & 1 if a household was affected by crop failure & 0.105 & 0.307 & 0 & 1 \\
\hline \multicolumn{6}{|c|}{ Coping strategy (Dummy) } \\
\hline saving & 1 if a household used its own saving for risk coping purpose & 0.346 & 0.476 & 0 & 1 \\
\hline govt & 1 if a household used the government programme for risk coping purpose & 0.045 & 0.208 & 0 & 1 \\
\hline transfer & $\begin{array}{l}1 \text { if a household used borrowing or transfer from relatives/friends } \\
\text { for risk coping purpose }\end{array}$ & 0.088 & 0.284 & 0 & 1 \\
\hline Capital depletion & $\begin{array}{l}1 \text { if a household depleted physical and human capital, reduced consumption } \\
\text { or changed crop choice for risk coping purpose }\end{array}$ & 0.088 & 0.283 & 0 & 1 \\
\hline other & 1 if a household used other strategies for risk coping purpose & 0.498 & 0.500 & 0 & 1 \\
\hline
\end{tabular}

The number of observations in the household characteristics is 10830 ( $5415 \mathrm{HHs}$ for each year).

The variables for shocks and coping strategy are available from 2006 survey and the number of observations is 5559 .

*: ICRISAT categorisation of agro-climatic condition

Humid - Length of Growing Period (LGP) $>180$ days

Semi-Arid temperature - LGP: $75-180$ days, Temp $<=18$ degree

Semi-Arid tropic - LGP: 75-180 days, Temp >= 18 degree

Arid - LGP $<75$ days 